\title{
Resistance to Persuasion: Examining the Influence of Political Ideology on COVID-19 Vaccine Uptake Hesitancy
}

\author{
Nancy H. Brinson * \\ University of Alabama, Tuscaloosa, AL, United States
}

The COVID-19 pandemic has contributed to the death of over 625,000 Americans and it continues to have monumental consequences worldwide for economic, social and individual life. An effective vaccine program is considered vital to securing collective immunity; yet, many Americans are still hesitant to be vaccinated. This two-part study first experimentally tests two message frames (inoculation vs control) designed to counter resistance to the COVID-19 vaccine with individuals who are initially supportive, neutral or opposed to it. Based on a key finding from Study 1 (that political ideology appears to be impacting receptiveness to the messaging), Study 2 examines response to these same

OPEN ACCESS

Edited by:

Seow Ting Lee,

University of Colorado Boulder, United States

Reviewed by: Douglas Ashwell, Massey University Business School, New Zealand

Elizabeth Williams, Colorado State University, United States

*Correspondence: Nancy $\mathrm{H}$. Brinson brinson@apr.ua.edu

Specialty section: This article was submitted to Health Communication, a section of the journal Frontiers in Communication

Received: 18 August 2021 Accepted: 01 November 2021

Published: 10 January 2022

Citation:

Brinson NH (2022) Resistance to Persuasion: Examining the Influence of

Political Ideology on COVID-19

Vaccine Uptake Hesitancy.

Front. Commun. 6:760847.

do: $10.3389 /$ fcomm.2021.760847 two messages using either a politicized (Dr. Anthony Fauci) or neutral source to test the mediating effects of political ideology. Results contribute to existing literature by examining inoculation effects in a new context ("debunking" misinformation vs "prebunking" to bolster supportive attitudes), and demonstrate how psychological reactance is working in tandem with inoculation to influence attitudes toward the COVID-19 vaccine.

Keywords: inoculation, psychological reactance theory (PRT), COVID-19, vaccine hesitancy, political ideology, threat, attitude certainty

\section{INTRODUCTION}

By every measure, the impact of the COVID-19 pandemic has been monumental to society. As of August 2021, the virus contributed to the death of over 625,000 Americans (Centers for Disease Control, 2021). It has also taken an enormous toll on mental health, leading to increased alcohol consumption, substance abuse and suicide rates (Panchal et al., 2020). An effective vaccination program is vital to securing collective immunity; yet, many Americans are hesitant to be vaccinated due to a variety of concerns. A study conducted prior to the vaccine's release found that $24 \%$ of Americans said they would definitely refuse it, and another $25 \%$ said they would probably refuse (Tyson et al., 2020). Fortunately, since the vaccine's release, these numbers have dropped to 9.5 and 13.9\% respectively (File and Mohanty, 2021). Although these numbers reflect a downward trend, a refusal rate of greater than $10 \%$ could impede a targeted vaccination rate of $82-85 \%$, which is the current estimate for achieving herd immunity against the COVID-19 virus (Read, 2020).

Contributing to Americans' resistance to the COVID-19 vaccine are their beliefs that vaccine development has not been adequately tested for safety or long term effects (60\%); virus mutation makes it unlikely the vaccine will be effective (37\%); perceived personal risk from COVID-19 is insufficient to warrant being vaccinated (19\%); vaccines are generally dangerous, stemming from medical community mistrust (20\%), and dissatisfaction with the government's pandemic response (including suspicions that the vaccine's response may be politically-motivated) (Ipsos, 2020). Many concerns expressed by those unwilling to take the vaccine appear to be influenced by demographic 
and psychological factors, such as political ideology and institutional trust, rather than factual information (Tyson et al., 2020).

Given the daily flood of information (and misinformation) bombarding Americans about COVID-19, it may be difficult for individuals to objectively evaluate every piece of information based on its merit. Misinformation about the COVID-19 vaccine can have significant societal consequences if it undermines scientific evidence about the seriousness of the virus's threat to public health (Benski et al., 2020). While social media sites have taken measures to crackdown on the spread of COVID vaccine misinformation (McGill and Sara Fischer, 2021), the responsibility for informing and educating the public about the importance of vaccine uptake must not rest solely with the media. Effective public interest campaigns are needed to promote positive and resistant attitudes toward vaccine uptake before the spread of misinformation becomes too firmly entrenched. A proven strategy worth examining is the use of tailored inoculation messaging designed to neutralize misinformation about the vaccine before it is firmly encoded.

Using a theoretical foundation of Inoculation and Psychological Reactance theories, this two-part study first experimentally tests two message frames (inoculation vs control) designed to counter resistance to the COVID-19 vaccine with individuals who are initially supportive, neutral or opposed to it. Then, it further tests response to these same two messages using either a politicized source (Dr. Anthony Fauci) or a neutral source to examine the mediating effects of political ideology. To date, few studies have considered inoculation effects across a full spectrum of pre-existing attitudes, and even fewer have considered the effect of political ideology on attitude change in a public health context. This work provides important insights about communication strategies designed to debunk misinformation and increase public willingness to consider taking the COVID-19 vaccine. It also extends theory by testing the effects of inoculation messaging on individuals with neutral and opposed attitudes who may experience reactance to that messaging based on the political orientation of the source. As such, this study offers new insights about the basic mechanisms driving inoculation and reactance processes, offering public interest communicators an effective strategy for increasing COVID-19 vaccine uptake.

\section{Inoculation Theory}

Considered the most consistent and reliable method for countering resistance to persuasion (Miller et al., 2013), Inoculation theory provides a powerful framework to measure the effect of messages intended to promote COVID-19 vaccine uptake. McGuire (1964) originally theorized that an attitude can be protected against counter influences in the same way a body can be protected from disease (through pre-exposure to weakened versions of an attitudinal threat). By presenting such two-sided messaging, individuals are theoretically motivated to resist subsequent attitudinal challenges through the processes of threat and counterarguing. Traditional inoculation messages introduce threat (a recognition of attitudinal vulnerability) among individuals who hold a position favorable to a cause or a brand, with the goal of motivating them to fortify their defenses and more strongly advocate (or counterargue) their positions (Ivanov, 2018). This method, known as "prebunking," has been shown to successfully reinforce positive attitudes through decades of experimental research in media effects (Banas and Rains, 2010), as well as foster resistance to negative health behaviors (Compton et al., 2016).

Recent scholars (Wood, 2007; Ivanov et al., 2017) have examined inoculation effects across all audiences (rather than just those who support a position), with a goal of understanding how inoculation might be used persuade those who are neutral or opposed to a cause. Others have expanded inoculation's processes into new contexts, including "therapeutic inoculation," which involves interventions designed to inoculate audiences who have already been afflicted with misinformation (Maertens, et al., 2020; Roozenbeek and Van der Linden 2019). This technique has been empirically shown to generate large-scale resistance against fake news related to climate change (Cook et al., 2017; Van der Linden et al., 2017) and COVID-19 (Van der Linden et al., 2020), even when the inoculation messaging did not align with respondents' prior attitudes.

Another recent departure from traditional inoculation research is the expectation of measuring attitude change longitudinally. Contemporary inoculation researchers differentiate between active vs passive inoculation (Maertens et al., 2020), noting that immediate debunking is critical with fake news, since some individuals will continue to believe it long after it has been discredited. Van der Linden and others (2017) demonstrated that in the context of climate change, the positive effects of a single exposure to a therapeutic inoculation can persist over time, but this outcome is dependent on high involvement and low attitude certainty about the issue. These new approaches extend inoculation effects research beyond protecting preexisting positive attitudes over time (prebunking) to understanding the effects of inoculation messaging on those with neutral or negative attitudes immediately following exposure (debunking). Given the current divided mindset and the mixed narrative currently being presented to Americans about the COVID-19 vaccine, Inoculation theory offers great potential for examining public response to persuasive messages designed to challenge misinformation about the vaccine across a full spectrum of attitudes and ideologies.

\section{Psychological Reactance Theory}

Psychological Reactance Theory (PRT) purports that individuals will react negatively when presented with a threat that is perceived to limit or eliminate a specific freedom or set of freedoms (Brehm, 1966). Reactance has been shown to motivate behaviors aimed at regaining any lost freedoms, along with the expression of negative attitudes and emotions. Perceived threats can be internal (choosing to limit one's own options), or external (when environmental factors limit one's ability to exert previously-held freedoms) (Brehm, 1966; Brehm and Brehm, 1981). PRT is relevant in this context because it provides an explanation for why pro-COVID-19 vaccination messages may be perceived as freedom threats, leading to negative outcomes. 
Recent scholars (Dillard and Shen, 2005) conceptualize reactance as an amalgamation of negative thoughts and feelings, which are characterized by an intertwining of cognitive (counterarguing) and affective (anger) components. Researchers utilizing PRT to examine communication outcomes have predominantly focused on identifying the message features most likely to stimulate and diminish reactance, including freedom-threatening language, provision of choice, message framing and empathetic narratives (Reynolds-Tylus, 2019). For example, Richards and Banas (2015) found that two-sided inoculation messages promoting empathy reduced freedom threat and reactance to anti-drinking messages as compared to a one-sided control message.

To better understand how inoculation and reactance might be working together to influence attitudes and behaviors related to the COVID-19 vaccine, this study considers key theoretical concepts from both theories and how they potentially interact in this context. Some of these concepts are theoretical (preexisting attitudes, perceived threat, and counterarguing); while others are context-specific (political ideology, institutional trust and attitude certainty).

\section{Pre-Existing Attitudes and Resistance}

To conduct effective inoculation testing, McGuire (1961) noted that attitudes must be measured prior to exposure to inoculation messaging to not only reveal the state of accepted beliefs, but to assess the vulnerability of attitudes prior to encountering a threat. Pfau et al. (2009) further asserted that attitudes regarding an issue must be firmly in place at the time of the inoculation, and there must be a division of opinions, both in support of and in opposition to positions regarding the issue. While inoculation has been traditionally used to bolster supportive attitudes toward an issue in anticipation of attack (Banas and Rains, 2010; Compton et al., 2016), recent studies indicate that inoculation can also be an effective strategy to influence audiences across a broader spectrum of attitudes. For example, Wood (2007) found that those with initially-neutral attitudes toward agricultural biotechnology reported significantly greater attitude change following exposure to inoculation messaging as compared to those with supportive or negative attitudes. Likewise, Ivanov and others (2017) found that inoculation messages about tourist destinations significantly influenced subjects with initially-neutral and opposing attitudes, but the effect sizes were small. In their study related to debunking misinformation about climate change, Van der Linden et al. (2017) found that inoculation messages pre-emptively protected respondents' attitudes from such misinformation across a polarized spectrum of beliefs.

These recent studies indicate that inoculation messaging has the potential to positively influence views about the COVID-19 vaccine across all attitudinal groups (serving to either prebunk or debunk existing beliefs); but it is particularly effective among those with neutral (or at least not yet strongly held) attitudes, suggesting the first hypothesis for this study:

H1: Among subjects exposed to the inoculation message, initially-neutral subjects will report greater positive attitude change than initially (a) supportive or (b) opposed subjects.

\section{Perceived Threat}

Threat is conceptualized as a perceived challenge to an existing belief (Compton and Ivanov, 2012), and considered a critical component of inoculation (Pfau, 1995). Perceived threat requires recognition that one's attitude about an issue is vulnerable to attack; and the efficacy of a threat is directly related to an individual's familiarity with (and ability to call on) counterattitudinal arguments (Compton and Ivanov, 2012). McGuire (1964) argued that overcoming unfamiliar counter-attitudinal arguments is more challenging than overcoming familiar ones, meaning novel arguments theoretically offer the greatest opportunity to trigger attitude change. Indeed, Miller and others (2013) demonstrated that individuals who were supportive or opposed to an issue are more likely to ignore or discount a challenge to their current beliefs if they have previously encountered it. However, Banas and Rains (2010) found no appreciable differences in the persuasiveness of threat messages featuring familiar versus novel content. Building on these previous studies, Richards et al. (2017) found that psychological reactance was a better predictor of response to inoculation messaging designed to decrease soda and alcohol consumption than previous familiarity with the message content.

Reasoning that they are less familiar with arguments about an issue (and their beliefs are not as firmly-established), Wood (2007) argued that neutral subjects are less likely to experience threat compared to supportive or opposed subjects. Thus, assuming respondents have different levels of familiarity with information surrounding the COVID-19 vaccine, it follows that neutral subjects should experience the lowest threat-related resistance to an inoculation message, suggesting:

H2: Initially-neutral subjects will report lower perceived threat from the inoculation message than initially (a) opposed or (b) supportive subjects.

\section{Counterarguing}

Conceptualized as an intention to defend pre-established attitudes, counterarguing is another critical component of the inoculation process. McGuire (1964) purported that by threatening individuals' beliefs, inoculation messages motivate them to bolster their defenses by counterarguing their position. Traditional inoculation research focused on counterarguing effects among supportive subjects; consequently, effective inoculation messaging was expected to provide content that supportive subjects could use to refute an attack on their beliefs (Compton and Pfau, 2005). However, since subjects initially-supportive of and opposed to the position advocated in a two-sided inoculation message theoretically experience threat, it may be expected that both groups will be triggered to counterargue (although the valence of their counterarguments will differ). Indeed, opposed subjects are likely to engage in "reverse counterarguing" (advocating an opposing point of view) to express their disagreement with the position advocated in the inoculation message (Wood, 2007).

Compton and Pfau (2005) demonstrated that since counterarguing is an interpersonal process, individuals in the digital age often seek attitudinal reassurance and practice advocacy via social media. While supportive subjects are likely 
to counterargue by sharing an inoculation message as presented with their social network (since it aligns with their beliefs), a prevalent form of reverse counterarguing among opposing subjects is sharing a message that directly refutes the content of an inoculation message in order to discredit it (Lee et al., 2014). In the current social media environment, there is ample evidence of counterarguing and reverse counterarguing about many issues, but it is especially prevalent regarding the COVID-19 vaccine (McGill and Sara Fischer 2021). Inoculation theory (in tandem with PRT) suggests that challenging an individual's beliefs elicits threat, which will motivate that individual to counterargue in order to re-establish freedom. Recent research (Chan and Ngai 2011) indicates that if a perceived threat motivates an individual to counterargue for or against a two-sided inoculation message, they are likely to share that message (or challenge it) with their social network, suggesting:

H3: Initially-neutral subjects exposed to the inoculation message will report lower counterarguing intent than initially (a) supportive or (b) opposed subjects.

\section{Political Ideology}

Political ideology has been defined as a set of attitudes containing cognitive, affective, and motivational components that organize an individual's values and beliefs (Tedin, 1987). In their examination of the role of political ideology in consumer reaction to multiple consumption regulations (e-cigarettes, food warning labels, and using mobile phones while driving), Irmack and others (2020) found that the position held by the political party that subjects support affects how they cognitively and affectively process information presented to them about an issue. Moreover, numerous studies demonstrate that political ideology is a key contributor to individuals' attitudes about the level of threat attributed to the COVID-19 virus (Cakanlar et al., 2020; Kelly et al., 2020; Nowlan and Zane 2020; Roozenbeek et al., 2020; Van der Linden et al., 2020), as well as the efficacy of the vaccine (Bechler and Tormala, 2020; Chou and Budenz, 2020; Tyson et al., 2020).

While conservatives are generally more sensitive to threats surrounding public health-related issues than liberals (Lilienfeld and Latzman, 2014; Crawford, 2017; Jost, 2017); liberals report greater sensitivity to threats about the COVID-19 pandemic (Barrios and Hochberg 2020). These ideological differences have been attributed to conservatives' greater tendency to view free will and self-determination as the primary drivers of outcomes in life, causing them to react negatively toward regulations perceived as restricting their freedom (Irmack et al., 2020). Political conservatives also tend to be more riskaverse than liberals (Baumgaertner et al., 2018); so depending on their estimation of the risks associated with taking the vaccine versus not, their political ideology will likely influence their attitudes and behaviors. Seibel and Dowd (2001) also found that conservatives are less concerned with social norms and maintain a higher desire for autonomy than liberals, suggesting they may be highly-reactant to new rules implemented for the betterment of society over the rights of individuals.

These findings indicate that political ideology likely influences individuals' attitudes about the COVID-19 vaccine; therefore, inoculation messaging intended to persuade conservatives needs to avoid triggering reactance by excluding freedom-threatening language (Reynolds-Tylus, 2019; Chou and Budenz 2020). That said, effective persuasion requires more than just compelling language. A message's source has also been found to significantly influence receptivity to various public health messages. For example, Baumgaertner et al. (2018) found that political ideology indirectly influenced parents' attitudes about vaccinating their children through their perceived trust in the health-related information sources. Moreover, Motta et al. (2021) and Nowlan and Zane (2020) demonstrated that the source of COVID-19 messaging was critical in determining perceived threat and attitude change related to the COVID-19 virus. Therefore, COVID-19 pro-vaccination messaging attributed to a source that triggers reactance based on the audience's political viewpoint is less likely be less effective; and based on the studies outlined above, suggests another hypothesis for this study:

H4: Conservative subjects will report higher perceived threat in response to the two-sided politicized message as compared to (a) the one-sided politicized message, (b) the one-sided neutral message or (c) the two-sided neutral message.

\section{Institutional Trust and Attitude Certainty}

While political ideology may help explain attitudes and behaviors related to the COVID-19 vaccine, scholars point to important antecedents of political ideology that may be playing a moderating role as well. According to a recent study, trust placed in the medical community and government experts has an effect on individuals' willingness to be vaccinated in general (Baumgaertner et al., 2018). In examining susceptibility to misinformation about COVID-19 vaccination in particular, Roozenbeek and others (2020) noted that lower trust in medical science and government experts also played a role in determining subjects' beliefs. Recent news reports (Leonhardt, 2021) and consumers surveys (Berg, 2020) also confirm how trust in medical and government institutions is influencing Americans' attitudes about the COVID-19 vaccine, suggesting these attitudes are becoming more entrenched.

Indeed, despite decreases in vaccine hesitancy since it first became available, those who say they will probably refuse the vaccine (about $25 \%$ of Americans) appear to have developed even greater attitude certainty in recent months (Braunstein et al., 2021). Since studies show that attitude certainty remains relatively stable over time (DeMarree et al., 2020), the current level of anti-vaccine attitude certainty is likely to remain unchanged without effective intervention. That said, studies indicate that presenting opposing messages to those confident of their attitudes could trigger reactance (Bechler and Tormala, 2020). Therefore, a clearer understanding of the antecedents and consequences driving individuals' attitude certainty about the COVID-19 vaccine is critical.

Research on the psychological foundations of attitude certainty suggest that factors such as information-seeking behavior (Kelly et al., 2020), having direct experience with the issue (Wu and Shaffer 1987); perceiving social support for one's attitude (Visser and Mirabile 2004), and the frequency of expressing an attitude about the issue (Holland et al., 2003) all 


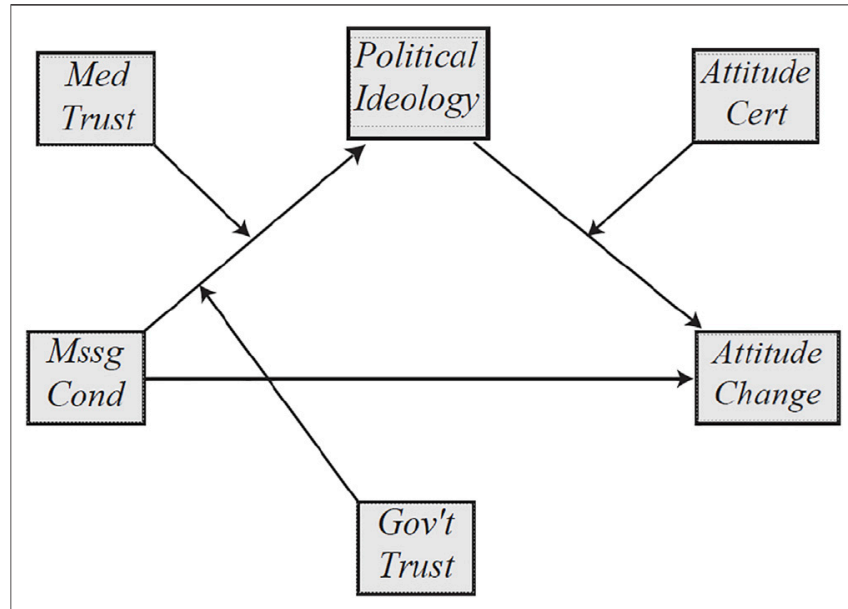

FIGURE 1 | Study 2 Moderated Mediation Model.

contribute to attitude certainty. Moreover, the so-called "bandwagon effect" (an individual's tendency to adopt a particular style, behavior or attitude because they believe everyone else is doing it), can strengthen or weaken attitude certainty (Li and Sundar 2021). Banas and Richards (2017) purport that perceived threat on its own does not consistently predict outcomes to inoculation messaging; rather, psychological states (like political ideology, trust in the source and attitude certainty) must be modeled as mediating variables that intervene between the message manipulation and persuasive outcomes. Based on these findings, the final hypothesis predicts:

H5: Political ideology (moderated by trust in the medical community, government, and attitude certainty) will mediate the direct effect of COVID-19 messaging on attitude change.

Figure 1 illustrates the proposed relationships between these variables.

\section{MATERIALS AND METHODS}

This study included two experiments, the first testing two message frames (inoculation vs control) to examine inoculation effects among those who were initially opposed, neutral or supportive of the COVID-19 vaccine; and the second to further test how these same messages were perceived by individuals who were liberal, moderate or conservative when incorporating a politicized versus a neutral message source. Both studies used a randomized pre-test/posttest design measuring immediate inoculation and reactance effects both within and between subjects.

\section{Measures}

Attitude toward the Vaccine was based on six items from a U.S. poll conducted by Ipsos (2020). Respondents rated their agreement (both pre and post-exposure) on a 12-point scale (1 = strongly disagree to 12 = strongly agree) with statements like "Taking the vaccine is the best way to prevent yourself from getting COVID-19". Pre-exposure attitudes $(M=6.98, S D=3.49$, $\alpha=0.92)$ were dummy coded into three groups, with mean scores $\leq 4.0$ categorized as "opposed" $(M=2.64, S D=1.24)$, scores ranging from 5.0 to 8.0 as "neutral" $(M=6.67, S D=1.22)$, and scores $\geq 9.0$ as "supportive" $(M=10.63, S D=1.19)$. Post-exposure attitudes were measured using the same scale $(M=7.37, S D=$ 3.51, $\alpha=0.94)$. Attitude change was the difference between postattitude and pre-attitude $(M=0.39, S D=1.52)$.

Perceived Threat was measured using Dillard and Shen (2005) 8 -item scale asking respondents to rate their agreement on statements like, "The message threatened my freedom" on a 7 point scale $(1=$ strongly disagree to $7=$ strongly agree $)(M=4.37$, $S D=1.70, \alpha=0.95)$.

Based on recent inoculation (Compton and Pfau, 2009) and reactance-based (Li and Sundar, 2021) studies, Counterarguing was conceptualized as respondents' social media sharing intent of the COVID-19 message presented using a 7-point bi-polar scale adapted from Kim et al. (2001). Options ranged from "Immediately post a comment about what's wrong with it" $(-3)$ to "Scroll past it and forget about it" (0), to "Immediately share it with my social network" $(+3)(M=1.27, S D=1.76)$.

Trust in Medical Community was measured using five items adapted from McKnight et al. (2002) scale. Participants indicated their agreement with statements like "I am comfortable relying on the medical community to meet its obligation to provide safe care for me and my family" based on a 7-point scale ( $1=$ strongly disagree, to $7=$ strongly agree $)(M=5.31, S D=1.08, \alpha=0.85)$.

Trust in Government was also measured using four items adapted from McKnight et al. (2002) scale. Participants indicated their agreement with statements like, "I am comfortable relying on U.S. government to meet its obligation to protect citizens" based on a 7 -point scale $(1=$ strongly disagree to $7=$ strongly agree $)(M=4.90, S D=1.41, \alpha=0.89)$.

Respondents' Political Ideology was measured using a 12-point bipolar scale [far left/liberal 1) to far right/conservative (12)], which was dummy coded into three groups. Mean scores $\leq 4.0$ were coded as "Liberal" $(M=2.8, S D=1.40)$, scores ranging from 5.0 to 8.0 as "Moderate" $(M=6.55, S D=1.85)$, and scores $\geq 9.0$ as "Conservative" ( $M=9.56, S D=1.85)$.

Attitude Certainty was measured using six items from Tormala and Rucker (2007) attitude certainty scale. Participants were asked to indicate their agreement on such statements as "My attitude on this topic is firm" and "I can defend my position if it is attacked" using a 10 -point scale ( $1=$ strongly disagree to $10=$ strongly agree $)$ $(M=7.01, S D=1.84, \alpha=0.91)$.

Table 1 summarizes each item along with the means, standard deviations and Cronbach's alpha for each composite variable.

\section{Study 1 Method}

Study 1 employed a 2 (inoculation vs control message) x 3 (opposed, neutral, or supportive pre-existing attitude) online experiment. Following a series of questions to determine their pre-existing attitudes, respondents were randomly assigned to see a social media post that either presented a two-sided inoculation message or a one-sided control message promoting the importance of COVID-19 vaccine uptake (see Figures 2, 3). Following exposure to the stimuli, participants' postintervention attitudes were measured by an online survey. 
TABLE 1 | Study Measures.

\begin{tabular}{|c|c|c|c|c|c|c|c|c|}
\hline \multirow[t]{2}{*}{ Construct } & \multirow[t]{2}{*}{ Source } & \multirow[t]{2}{*}{ Items } & \multicolumn{3}{|c|}{ Study 1} & \multicolumn{3}{|c|}{ Study 2} \\
\hline & & & $\alpha$ & Mean & SD & $\alpha$ & Mean & SD \\
\hline \multirow[t]{6}{*}{$\begin{array}{l}\text { Attitude toward the } \\
\text { Vaccine }\end{array}$} & Ipsos (2020) 12-point scale & $\begin{array}{l}\text { Taking the vaccine is the best way to prevent yourself from getting } \\
\text { COVID-19 }\end{array}$ & 0.92 & 6.98 & 3.49 & 0.91 & 7.56 & 2.86 \\
\hline & & $\begin{array}{l}\text { Taking the vaccine is the best way to prevent others from getting } \\
\text { COVID-19 }\end{array}$ & 0.94 & 7.37 & 3.51 & 0.92 & 7.77 & 2.86 \\
\hline & & $\begin{array}{l}\text { The best way to protect our community health is to get enough people } \\
\text { vaccinated }\end{array}$ & - & - & - & - & - & - \\
\hline & & The only way to save our economy is to get enough people vaccinated & - & - & - & - & - & - \\
\hline & & I would be angry if other healthy people refuse to get the vaccine & - & - & - & - & - & - \\
\hline & & Those who refuse to get the vaccine are ignoring science & - & - & - & - & - & - \\
\hline \multirow[t]{3}{*}{ Pre-Attitude Groups } & Ipsos (2020) & 1.0 to $4.0=$ Opposed $(n=129)-23.4 \%$ & - & 2.64 & 1.24 & - & 3.45 & 1.95 \\
\hline & & 4.5 to $8.0=$ Neutral $(n=207)-37.5 \%$ & - & 6.67 & 1.22 & - & 7.38 & 0.82 \\
\hline & & 8.5 to $12.0=$ Supportive $(n=216)-39.1 \%$ & - & 10.63 & 1.19 & - & 10.19 & 0.92 \\
\hline \multirow[t]{4}{*}{ Perceived Threat } & $\begin{array}{l}\text { Dillard and Shen (2005) 7-point } \\
\text { scale }\end{array}$ & $\begin{array}{l}\text { The message threatened my freedom The message tried to } \\
\text { manipulate me }\end{array}$ & 0.94 & 3.10 & 1.51 & 0.95 & 4.37 & 1.70 \\
\hline & & $\begin{array}{l}\text { The message tried to make a decision for me The message tried to } \\
\text { pressure me }\end{array}$ & - & - & - & - & - & - \\
\hline & & $\begin{array}{l}\text { The message made me feel angry The message made me feel annoyed } \\
\text { The message made me feel irritated }\end{array}$ & - & - & - & - & - & - \\
\hline & & The message made me feel agravated & - & - & - & - & - & - \\
\hline \multirow[t]{7}{*}{ Counterarguing Intent } & $\begin{array}{l}\text { Kim et al. }(2001) 7 \text {-point bi- } \\
\text { polar scale }(-3 \text { to }+3)\end{array}$ & $\begin{array}{l}\text { If that message you just saw appeared on your social media feed, you } \\
\text { would ... (-3) Immediately post a comment about what's wrong with it }\end{array}$ & - & 0.12 & 1.71 & - & 1.27 & 1.77 \\
\hline & & (-2) Indicate my disagreement with a negative emoticon & - & - & - & - & - & - \\
\hline & & $\begin{array}{l}(-1) \text { Do nothing, but tell friends I saw "fake news" about the COVID-19 } \\
\text { vaccine }\end{array}$ & - & - & - & - & - & - \\
\hline & & Scroll past and forget about it & - & - & - & - & - & - \\
\hline & & $\begin{array}{l}\text { Do nothing, but tell friends I saw some good news about the COVID-19 } \\
\text { vaccine }\end{array}$ & - & - & - & - & - & - \\
\hline & & Indicate my agareement with a positive emoticon & - & - & - & - & - & - \\
\hline & & Immediately share it with my social network & - & - & - & - & - & - \\
\hline \multirow[t]{5}{*}{ Medical Trust } & $\begin{array}{l}\text { Mcknight et al.(2002) 7-point } \\
\text { scale }\end{array}$ & $\begin{array}{l}\text { The medical community is interested in the well being of patients more } \\
\text { than its own }\end{array}$ & - & - & - & 0.85 & 5.31 & 1.08 \\
\hline & & $\begin{array}{l}\text { I am comfortable relying on the U.S. medical community to meet its } \\
\text { obligation to provide safe care for me and my family }\end{array}$ & - & - & - & - & - & - \\
\hline & & $\begin{array}{l}\text { I feel assured that legal structures adequately protect me from } \\
\text { problems I might have with the U.S. medical community }\end{array}$ & - & - & - & - & - & - \\
\hline & & $\begin{array}{l}\text { If a patient requires help, I believe the U.S. medical community would } \\
\text { do its best to help }\end{array}$ & - & - & - & - & - & - \\
\hline & & $\begin{array}{l}\text { I feel confident that medical advances make it safe for me to seek } \\
\text { treatment from the U.S. medical community }\end{array}$ & - & - & - & - & - & - \\
\hline \multirow[t]{4}{*}{ Government Trust } & $\begin{array}{l}\text { McKnight et al.(2002) 7-point } \\
\text { scale }\end{array}$ & $\begin{array}{l}\text { The U.S. government is interested in the well-being of its citizens more } \\
\text { than its own }\end{array}$ & - & - & - & 0.89 & 4.90 & 1.41 \\
\hline & & $\begin{array}{l}\text { I am comfortable relying on the U.S. government to meet its obligation } \\
\text { to protect citizens }\end{array}$ & - & - & - & - & - & - \\
\hline & & $\begin{array}{l}\text { I feel assured that legal structures adequately protect me from } \\
\text { problems I might have with the U.S. government }\end{array}$ & - & - & - & - & - & - \\
\hline & & $\begin{array}{l}\text { If a U.S. citizen requires help, I believe the government wouild do its } \\
\text { best to help }\end{array}$ & - & - & - & - & - & - \\
\hline \multirow[t]{5}{*}{ Attitude Certainty } & Tormala and Rucker (2007) & My attitude on this topic is firm & - & - & - & 0.91 & 7.01 & 1.84 \\
\hline & 10-point scale & I hold the correct attitude on this topic & - & - & - & - & - & - \\
\hline & & $\begin{array}{l}\text { My attitude will not change even if I find out the majority of people } \\
\text { disagree with me I can defend my position if it is attacked }\end{array}$ & - & - & - & - & - & - \\
\hline & & $\begin{array}{l}\text { I can maintain my position even if I encounter strong arguments } \\
\text { against it }\end{array}$ & - & - & - & - & - & - \\
\hline & & $\begin{array}{l}\text { I could confidently argue my position with someone who disagrees } \\
\text { with me }\end{array}$ & - & - & - & - & - & - \\
\hline \multirow[t]{4}{*}{ Political Ideology } & 12 pt bi-polar scale & Far Left Liberal (1) Far Right Conservative (12) & - & - & - & - & 6.70 & 3.94 \\
\hline & & 1.0 to $4.0=$ Liberal $(n=168)-30.6 \%$ & - & - & - & - & 2.80 & 1.40 \\
\hline & & 5.0 to $8.0=$ Moderate $(n=183)-33.4 \%$ & - & - & - & - & 6.55 & 1.85 \\
\hline & & 9.0 to $12.0=$ Conservative $(n=197)-35.9 \%$ & - & - & - & - & 9.56 & 1.75 \\
\hline
\end{tabular}




\section{Physician's Medical Group}

We have been continually stressing the importance of protecting ourselves and our communities from the COVID-19 virus. But after one of our employees lost a family member to this deadly disease last week, we are now speaking to you based on our personal exferience. We know you've heard some people say 'Don't let fears about COVID-19 dominate your life", but we've seen it kill too many patients, young and old. At the same time. we've all seen the impact that managing this virus is having on our communities. Continuing restrictive lockdowns threaten the quality of our children's education, our jobs, our mental health and the ivelihood of our small husinesses. So what ran we dn? It's simple - as smon as you have the opportunity, get vaccinated! The CDC has now approved the use of three vaccines for the prevention of COVID-19 in the U.S. If $80 \%$ of Americans are vaccinated, we can achieve herd immunity and get our lives back to normal. We've all heard the argument that the benefits of new vaccines don't outweigh the risks. However, the risk associated with these vaccines is mld to moderate symptoms for $1-3$ days, and the benefit is that the' are $95 \%$ effective in preventing COVID-19. Ask yourself -- are my current beliefs about the vaccine based on all of the facts, or am I being manipulated by unfounded fears? It's time for us to pull togethe: and take back our country from this devastating virus. We can only accomplish that if we all do our part and get vaccinated!

Do like Ocomment 2 snare

FIGURE 2 | Study 1 Inoculation Message.

Consistent with previous studies (Pfau et al., 2009; Miller et al., 2013; Ivanov, 2018), the inoculation message in this study incorporated two-sided language (offering support, defense, and refutational features) about the vaccine in order to elicit inoculation. It also included a mix of cognitive appeals supported by evidence, along with affective appeals designed to enhance empathy (Pfau et al., 2005). Alternatively, the control message presented one-sided language in support of the vaccine taken directly from the CDC website. It utilized a factual tone and did not present argumentative facts nor emotional language. Both messages in Study 1 featured text only and they were attributed to health or government entities rather than individuals to control for effects related to the message source.

\section{Study 1 Participants}

Study 1 included a representative U.S. sample recruited through Dynata and paid for their participation. A power analysis with a significance level of 0.05 at 0.80 power indicated a required sample of 41 participants per condition (246 total). A total of 458 respondents ( $56.8 \%$ female), $18-81$ years old $(M=41.7, S D=$ $17.4)$, primarily Caucasian (77.4\%), with some college education (71.1\%); and a median household income of $\$ 50,000-60,000$ completed the study. Among participants, 23.9\% reported being initially opposed to the COVID- 19 vaccine, $41.4 \%$ were neutral and $34.6 \%$ were supportive.

\section{Study 1 Results}

To confirm that the message manipulation was effective, an independent sample $t$-test was conducted to determine differences in counterarguing intent across conditions.
Centers for Disease Control and Prevention coc 24/7. Soving unes. Anotocting pocolier

In an effort to stop the spread of the novel coronavirus (COVID-19) that has killed over 500,000 Americans to date, the Centers for Disease Control has been working with drug manufacturers all over the world to develop a safe and effective vaccine. Although there is currently no FDA-approved vaccine to prevent COVID-19, the Adviscry Committee on Immunization Practices (ACIP) has issued interim recommendations for the use of Pfizer BioNTech, Moderna, anc Johnson \& Johnson Janssen COVIC-19 vaccines for the prevention of COVID-19 in the United States. These interim treatments are informed by data submitted to the FDA for Emergency Use Authorization (EUA) along with expert opinion on general best practice guidelines for immunization. Postvaccination symptoms are being reported as generally mild to moderate in severity. They typically occu' within the first three days of vaccination, and resolve within 1-3 days of onset. Preliminary results suggest these vaccines provide an efficacy rate of around $95 \%$ in preventing COVID.19. Health experts presict a vaccination rate of around $80 \%$ will be required to achieve herd immunity. As scon as any COVID-19 vaccine is offered to you, please schedule an appointment with your healthcare provider to be immunized.

$$
\text { D Like } \bigcirc \text { comment } A \text { Share }
$$

FIGURE 3 | Study 1 Control Message.

Previous studies (e.g., Wood 2007; Compton and Pfau, 2009; Ivanov 2018) used this as a primary measure of inoculation effects in other contexts. Results confirmed that significantly greater counterarguing intent was associated with the inoculation message $(M=0.24, S D=1.75)$ versus the control $(M=0.10$, $S D=1.67), t(442)=2.16, p=0.03$, indicating that the message manipulation was effective.

An ANOVA found a significant interaction between preexisting attitude and attitude change for the inoculation message $[F(2,223)=10.32, p=0.00]$. Post hoc tests showed that initially-neutral subjects exposed to the inoculation message reported greater attitude change than supportive subjects $(M D=$ $0.92, p=0.00$ ), thus H1a was supported. However, neutral subjects did not report a significantly greater attitude change compared to opposed subjects $(M=-0.45, p=0.11)$, so H1b was not supported.

An ANOVA found a marginally-significant interaction between pre-existing attitude and perceived threat for the inoculation message $[F(2,223)=2.51, p=0.08]$. Post hoc tests showed that although initially-neutral subjects reported lower perceived threat from the inoculation message than opposed subjects, it was not significant $(M D=-0.22, p=0.39)$, so H2a was not supported. Also, initially-neutral subjects reported higher perceived threat than supportive subjects exposed to the inoculation message $(M D=$ $0.41, p=0.05)$, therefore $\mathrm{H} 2 \mathrm{~b}$ was not supported.

An ANOVA found a significant interaction between preexisting attitude and counterarguing for the inoculation message $[\mathrm{F}(5,342)=9.71, p=0.01]$. Post hoc tests showed that initially-neutral subjects exposed to the inoculation message 
reported significantly lower counterarguing intent than supportive subjects $(M D=-0.44, p=0.04)$, so $\mathrm{H} 3 \mathrm{a}$ was supported. However, initially-neutral subjects reported higher counterarguing intent than opposed subjects $(M D=1.22, p=$ $0.00)$, so $\mathrm{H} 3 \mathrm{~b}$ was not supported.

\section{Study 1 Discussion}

This first experiment tested if inoculation messaging could positively impact the attitudes of participants with initiallyneutral and opposing views about the COVID-19 vaccine. Consistent with previous studies (Wood, 2007; Ivanov et al., 2017), results indicate that two-sided inoculation messaging offers promising potential with initially-neutral subjects; however, this outcome was not consistent among opposed subjects. One possible explanation for this result is that at the time this study was conducted (just prior to the release of the vaccine), attitudes about the COVID-19 vaccine may not have been firmly established, limiting predictable inoculation effects (Pfau et al., 2009). Or perhaps, as Cook and others (2017) suggested, the inoculation message successfully shifted some initially-opposed subjects' attention away from their cognitive biases (limiting perceived threat and contributing to positive attitude change), but others were not so easily persuaded for reasons not accounted for by this study.

Another unexpected result was that although perceived threat associated with the inoculation message was highest among the initially-opposed group $(M=3.39)$, it was not significantly different from the neutral group. Indeed, the lowest perceived threat for the inoculation message was reported by the supportive group $(M=2.77)$. Inoculation theory maintains that threat is generated by the recognition that one's attitude on an issue is vulnerable to attack; therefore, it was assumed that neutral subjects would experience less threat than supportive subjects. Given these results, perhaps supportive subjects had greater attitude certainty about the positive aspects of the COVID-19 vaccine, so they did not experience threat from the inoculation message. As Miller et al. (2013) demonstrated, individuals who are supportive of an issue are more likely to ignore or discount a challenge to their current beliefs if they have previously encountered it (thus lowering the message's perceived threat).

As expected, initially-supportive subjects were significantly more likely to share the message with their social network (counterargue) than neutral subjects, regardless of the message condition. However, opposed subjects were significantly less likely to counterargue than their neutral counterparts, meaning they did not intend to share the message with their social network (even to rebut it). This finding suggests that something other than perceived threat was driving the opposed subjects' response. Perhaps opposed subjects experienced reactance to the message, and this perceived threat to their freedom motivated them to stifle any further discussion of the topic with their social network. Or, since both messages were attributed to either medical or government sources, it is possible that distrust in these entities influenced this outcome as well.

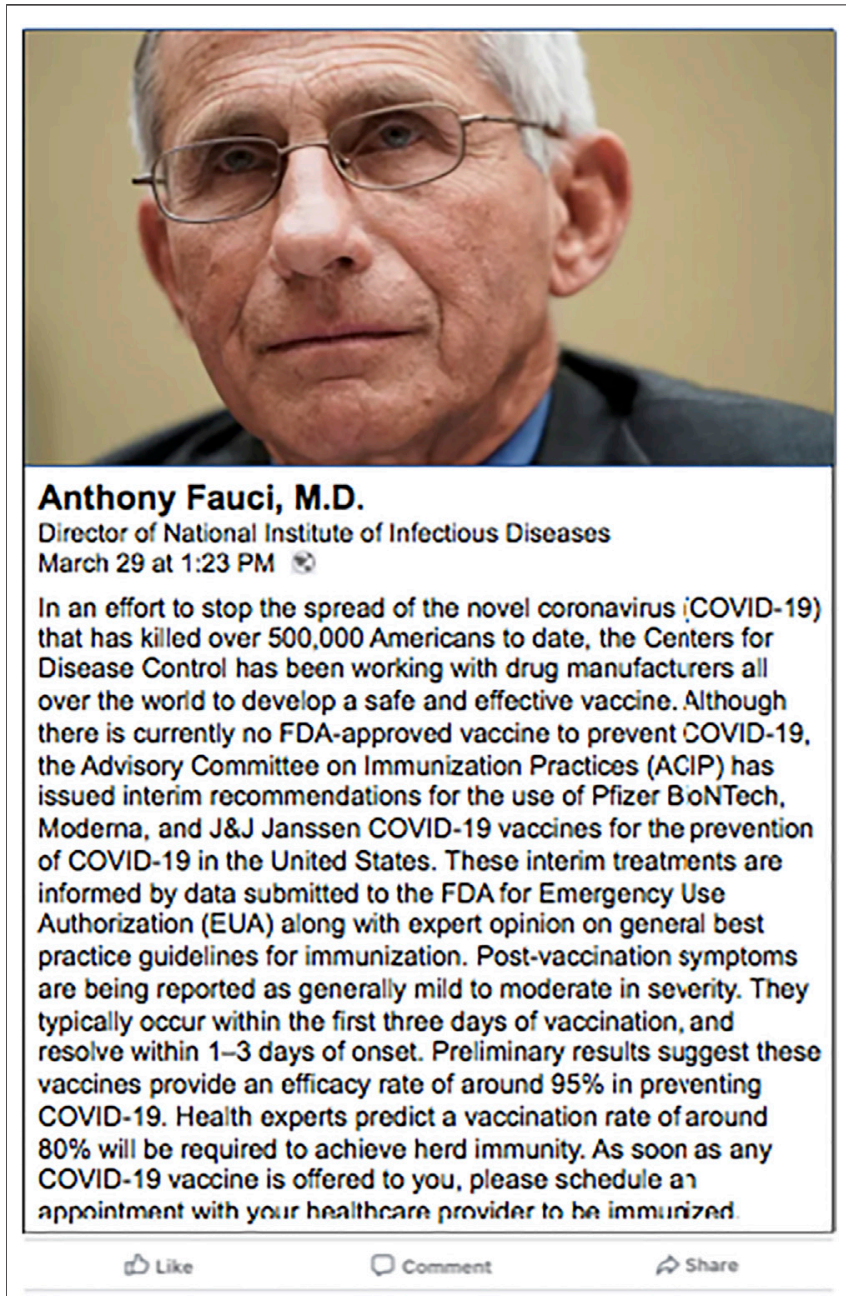

FIGURE 4 | Study 2 One-Sided Politicized Source Message.

Most public health messaging relies on an information-deficit (Baumgaertner et al., 2018) or informational flow (Gonella et al., 2020) approach to educate people on the risks and benefits of vaccination. However, the results of Study 1 demonstrate that factual information is not the only consideration driving subjects' attitudes about the COVID-19 vaccine. Recent studies indicate that individuals' political ideology strongly influences their perceptions and acceptance of risk (Cakanlar et al.,. 2020; Nowlan and Zane, 2020; Roozenbeek et al., 2020; Van der Linden et al., 2020), making it of particular importance in determining vaccine attitudes. To further test the efficacy of inoculation messaging, a second study was designed to examine the antecedents shown to influence consumer attitudes and behaviors in this context (political ideology, trust in the message source and attitude certainty).

\section{Study 2 Method}

Study 2 employed a 2 (inoculation vs control message) x 2 (politicized vs neutral source) x 3 (liberal, moderate vs conservative ideology) online experiment testing attitudinal 


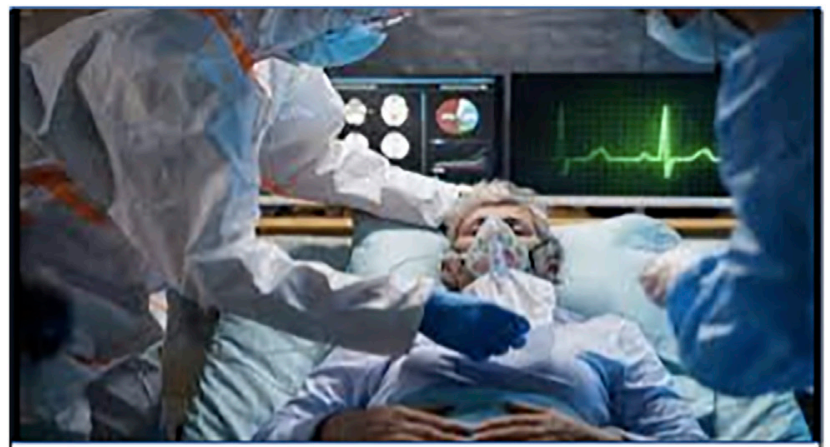

Scott Reynolds, M.D.

March 29 at 1:23 PM 8

In an effort to stop the spread of the novel coronavins (COVID-19) that has killed over 500,000 Americans to date, the Centers for Disease Control has been working with drug manufacturers all over the world to develop a safe and effective vaccine. Although there is currently no FDA-approved vaccine to prevent COVID-19, the Advisory Committee on Immunization Practices (ACIP) has issued interim recommendations for the use of Pfizer BioNTech, Moderna, and J\&J Janssen COVID-19 vaccines for the prevention of COVID-19 in the United States. These interim treatments are informod by data submitted to the FDA for Emergency Use Authorization (EUA) along with expert opinion on general best practice guidelines for immunization. Post-vaccination symptoms are being reported as generally mild to moderate in severity. They typically occur within the first three days of vaccination, and resolve within 1-3 days of onset. Preliminary results suggest these vaccines provide an efficacy rate of around $95 \%$ in preventing COVID-19. Health experts predict a vaccination rate of around $80 \%$ will be required to achieve herd immunity. As soon as any COVID-19 vaccine is offered to you, please schedule an appointment with your healthcare provider to be immunized.

DS Like $D$ comment $A$ Share

FIGURE 5 | Study 2 One-Sided Neutral Source Message.

change of respondents based on their political ideology. Respondents were randomly assigned to see a social media post that presented the same inoculation or control message promoting COVID-19 vaccine uptake that was attributed to Dr. Anthony Fauci or an anonymous doctor (see Figures 4, 5, 6, 7). The same language tested in Study 1 was used for the inoculation and control messages in Study 2; the only change to the stimuli was the incorporation of the name and photograph of either Dr. Anthony Fauci or an anonymous, fictional doctor as the source of the message. Dr. Fauci was chosen as the politicized source due to his demonstrated unpopularity among conservatives (Creitz, 2021). Following exposure to one of the four stimuli, participants' post-intervention attitudes were measured by an online survey.

\section{Study 2 Participants}

Study 2 included a representative U.S. sample recruited through Amazon Mechanical Turk and paid for their participation. A power analysis with a significance level of 0.05 at 0.80 power indicated the required sample of 43 participants per condition (516 total). A total of 543 U.S. respondents (58.5\% male) aged $18-79$ years old $(M=40.9, S D=17.2)$ completed the study. They

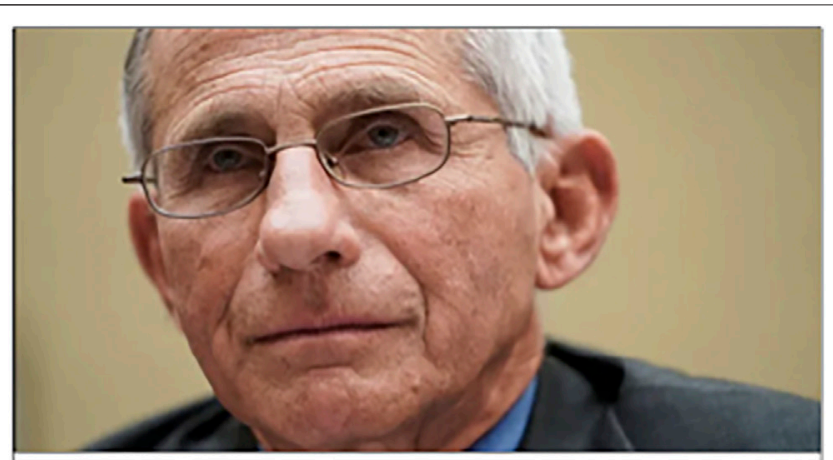

Anthony Fauci, M.D.

Director of National Institute of Infectious Diseases March 29 at 1:23 PM 8

I've spoken at length in my professional capacity about the importance of protecting ourselves and our communities from the COVID-19 virus. But after losing one of my own family members to this deadly disease last week, I am now speaking to you based on my personal experience. I know you've heard some people say "Don't let fears about COVID-19 cominate your life", but l've seen it kill too many patients, young and old. At the same time, we've all seen the impact that managing this virus is having on our communities. Restrictive lockdowns threaten the quality of our children's education, our jobs, our mental health and the livelinood of our small businesses. So what can we do? It's simple - as scon as you have the opportunity, get vaccinated! The CDC has now approved the use of three vaccines for the prevention of COVID-19 in the U.S. If $80 \%$ of Americans are vaccinated, we can achieve hord immunity and got our livoo back to normal. Wovo all hoard tho argument that the benefits of new vaccines don't ourweigh the risks. However, the risk associated with these vaccines is mild to moderate sympioms for 1-3 days, and the benefit is that they are $95 \%$ effective in preventing COVID-19. Ask yourself -- are my current beliefs about the vaccine based on all of the facts, or am I being manipulated by unfounded 'ears? It's time for us to pull together and take back our country from this devastating virus. We can only accomplish that if we all do our part and get vaccinated!

$$
\text { DL Like D conment share }
$$

FIGURE 6 | Study 2 Two-Sided Politicized Source Message.

were primarily Caucasian (70.1\%), college graduates $(51.3 \%)$; with a median household income of $\$ 50,000-60,000$. Their reported political ideologies were $30.4 \%$ liberal, $33.2 \%$ moderate, and $36.4 \%$ conservative.

\section{Study 2 Results}

Two independent sample t-tests confirmed that respondents reported significantly greater counterarguing intent for the inoculation message $(M=1.49, S D=1.78)$ as compared to the control $(M=1.03 S D=1.73), t(523)=2.48, p=0.01$. Likewise, respondents reported significantly greater counterarguing intent for the politicized $(M=1.42, S D=1.74)$ versus the neutral message source $(M=1.04, S D=1.43), t(523)=2.23, p=0.03$, indicating that both message manipulations were effective.

An ANOVA did not find a significant relationship between political ideology and perceived threat across message conditions $[\mathrm{F}(3,196)=0.27, p=0.85]$. Moreover, post hoc tests showed that conservative subjects reported lower perceived threat when exposed to the two-sided politicized message $(M=5.02)$ as 


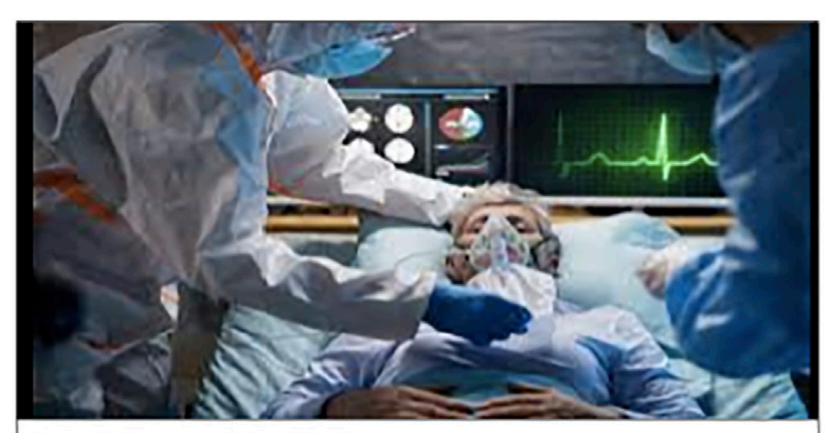

Scott Reynolds, M.D.

March 29 at 1:23 PM \&

I've spoken at length in my professional capacity about the importance of protecting ourselves and our communities from the COVID-19 virus. But after losing one of my own family members to this deadly disease last week, I am now speaking to you based on my personal experience. I know you've heard some people say "Don't let fears abou: COVID-19 dominate your life", but l've seen it kill too many patients, young and old. At the same time, we've all seen the impact that managing this virus is having on our communities. Restrictive lockdowns threaten the quality of our children's education, our jobs, our mental health and the livelihood of our small businesses. So what can we do? It's simple - as scon as you have the opportunity, get vaccinated! The CDC has now approved the use of three vaccines for the prevention of COVID-19 in the U.S. If $80 \%$ of Americans are vaccinated, we can achieve herd immunity and get our lives back to normal. We've all heard the argument that the benefits of new vaccines don't outweigh the risks. However, the risk associated with these vaccines is mild to moderate symptoms for $1-3$ days, and the benefit is that they are $95 \%$ effective in preventing COVID-19. Ask yourself -- are my current beliefs about the vaccine based on all of the facts, or am I being manipulated by unfounded fears? It's time for us to pull together and take back our country from this devastating virus. We can only accomplish that if we all do our part and get vaccinated!!

$$
\text { d) Like }
$$$$
\square \text { comment }
$$$$
\text { A share }
$$

FIGURE 7 | Study 2 Two-Sided Neutral Source Message.

compared to the one-sided politicized message $(M=5.20)$, the onesided neutral message $(M=5.24)$, or the two-sided neutral message $(M=5.18)$, therefore $\mathrm{H} 4 \mathrm{a}, \mathrm{H} 4 \mathrm{~b}$ and $\mathrm{H} 4 \mathrm{c}$ were not supported.

Hypothesis 5 predicted that political ideology (moderated by trust in the medical community, government, and attitude certainty) will mediate the direct effect of the COVID-19 messaging framing on attitude change. Using PROCESS SPSS macro, message condition was entered as the independent variable $(\mathrm{X})$, attitude change was the dependent variable $(\mathrm{Y})$, political ideology was the mediator (M), and trust in the medical community (W), trust in government (Z), and attitude certainty (V) were entered as moderators (Model 23). Two models separately assessed the influence of message condition on attitude change: indirect path $\mathrm{B}$ (message condition-political ideology-attitude change), which was significant $[\mathrm{F}(5,543)=$ 2.121, $p=.050$ ]; and direct path C' (message condition-attitude change), which was not significant $[\mathrm{F}(3,543)=.011, p=.999]$. Taken together, these findings indicate that political ideology (moderated by medical trust, government trust, and attitude certainty) did have a mediating effect on attitude change; therefore, H5 was supported.
In looking at the variables individually, government trust was the only significant moderator on political ideology $(t(20,528)=$ -1.519, $p=0.013$ ), and the unconditional interaction between message condition and government trust $\left(X^{\star} Z\right)$ was also significant $(p=0.047)$. Medical trust did not have a significant moderating effect on political ideology $(t(20,528)=0.662, p=$ $0.508)$, and the interaction between message condition and medical trust $\left(\mathrm{X}^{\star} \mathrm{W}\right)$ was also not significant $(p=0.870)$.

Interestingly, none of four message conditions independently had a significant indirect effect on attitude change; however, political ideology $(t(5,543)=-2.234, p=0.026)$ and attitude certainty $(t(5$, $543)=-2.455, p=0.014)$ both had significant negative effects, suggesting that these two variables were overriding any messaging effects in this study. That said, the one-sided neutral message did have a significant partial moderated mediation with government trust (index $=-0.134$ ), meaning as respondents' political ideology became more conservative, they were less likely to trust government in this context. Table 2 provides detailed results for every relationship in the moderated mediated model.

\section{Study 2 Discussion}

Using tenets from both Inoculation and Psychological Reactance theories, this second study sought to examine the mediating role of the political ideology of the source in predicting attitude change about the COVID-19 vaccine. While significant results were found for the model overall, there were some unexpected findings, suggesting that while this blended theoretical approach is useful, additional research is needed to enhance understanding of these complex and interdependent relationships.

First, Inoculation theory predicts that perceived threat is critical to attitude change; however, in this study, conservative subjects reported the lowest level of perceived threat in response to the twosided politicized message as compared to the other conditions. Based on recent research related to the effect of political ideology on attitudes about the COVID-19 vaccine (Roozenbeek et al., 2020; Van der Linden et al., 2020), conservative subjects should have reported the highest level of threat from the politicized inoculation message since it featured a controversial source, Dr. Anthony Fauci, who is not well-regarded by their political peers. That said, McGuire (1964) purports that the efficacy of an inoculation message is directly related to an individual's familiarity with (and confidence in) the facts presented. Perhaps due to the enormous stream of information (and misinformation) circulated about the COVID-19 vaccine, conservative subjects' attitudes about the vaccine were already established, so they considered the politicized message as fake news and simply disregarded it. Or, perhaps conservatives perceived the politicized message as manipulative and/or an attempt to limit their freedom, so their reactance led them to quickly dismiss it without fully processing the content.

This explanation is supported by the results of the integrated model, which showed that when political ideology served as a mediator, there were significant differences in attitude change between the message conditions. That said, although different effects (ranging from positive to negative) were reported for each of the message conditions, none of them were significant to the outcome of attitude change independently. As shown in Table 2, the variables offering the most significant effects in the model 
TABLE 2 | Moderated Mediation Model Statistics.

\begin{tabular}{|c|c|c|c|c|c|c|}
\hline \multicolumn{7}{|c|}{$\begin{array}{l}\text { Outcome variable: Political ideology (mediator) } \\
\text { Model summary }\end{array}$} \\
\hline $\mathrm{R}$ & R-sq & MSE & $\mathrm{F}$ & $\mathrm{df1}$ & $\mathrm{df} 2$ & $\mathrm{P}$ \\
\hline 0.262 & 0.069 & 0.642 & 1.942 & 20.000 & 528.000 & 0.009 \\
\hline- & coeff & se & $\mathbf{T}$ & $\mathbf{p}$ & LLCI & ULCI \\
\hline Constant (1-Sided/Political) & 0.195 & 0.405 & 0.482 & 0.000 & 1.158 & 2.749 \\
\hline X1 (1-Sided/Neutral) & -0.186 & 0.433 & -0.429 & 0.668 & -1.037 & 0.665 \\
\hline X2 (2-Sided/Political) & -0.038 & 0.485 & -0.078 & 0.938 & -0.990 & 0.915 \\
\hline X3 (1-Sided/Neutral) & 0.185 & 0.466 & 0.396 & 0.692 & -0.731 & 1.100 \\
\hline Medical Trust & 0.269 & 0.406 & 0.662 & 0.508 & -0.551 & 0.960 \\
\hline Government Trust & -0.350 & 0.231 & -1.519 & 0.013 & -0.803 & -0.103 \\
\hline - & R2-chng & - & $\mathbf{F}$ & df1 & df2 & $\mathbf{P}$ \\
\hline COND * MED TRUST & 0.004 & - & 0.413 & 6.000 & 528.000 & 0.870 \\
\hline COND * GOVT TRUST & 0.107 & - & 1.613 & 6.000 & 528.000 & 0.047 \\
\hline \multicolumn{7}{|c|}{$\begin{array}{l}\text { Outcome Variable: Attitude Change } \\
\text { Model Summary }\end{array}$} \\
\hline $\mathrm{R}$ & R-sq & MSE & $\mathrm{F}$ & $\mathrm{df1}$ & $\mathrm{df} 2$ & $\mathrm{P}$ \\
\hline 0.138 & 0.019 & 1.617 & 2.121 & 5.000 & 543.000 & 0.050 \\
\hline- & coeff & se & $\mathbf{T}$ & $\mathbf{p}$ & LLCI & ULCI \\
\hline Constant (1-Sided/Political) & 0.003 & 0.267 & 0.011 & 0.992 & -0.522 & 0.527 \\
\hline X1 (1-Sided/Neutral) & 0.011 & 0.156 & 0.073 & 0.994 & -0.302 & 0.304 \\
\hline X2 (2-Sided/Political) & -0.023 & 0.152 & -0.149 & 0.881 & -0.322 & 0.277 \\
\hline X3 (1-Sided/Neutral) & -0.010 & 0.155 & -0.065 & 0.948 & -0.314 & 0.294 \\
\hline Political Ideology* & -0.149 & 0.067 & -2.234 & 0.026 & -0.280 & -0.018 \\
\hline Attitude Certainty & -0.073 & 0.030 & -2.455 & 0.014 & -0.015 & -0.132 \\
\hline \multicolumn{7}{|c|}{ Direct Effects } \\
\hline- & Effect & se & $\mathbf{T}$ & $\mathbf{p}$ & LLCI & ULCI \\
\hline$X 1$ & 0.001 & 0.154 & 0.007 & 0.994 & -0.522 & 0.527 \\
\hline $\mathrm{X} 2$ & -0.023 & 0.152 & -0.149 & 0.881 & -0.322 & 0.277 \\
\hline X3 & -0.010 & 0.155 & -0.065 & 0.948 & -0.314 & 0.294 \\
\hline Omnibus Direct Effect & R2-chng & - & $\mathbf{F}$ & df1 & df2 & $\mathbf{P}$ \\
\hline$X$ on $Y$ & 0.000 & - & 0.011 & 3.000 & 543.000 & 0.999 \\
\hline \multicolumn{7}{|c|}{ Indirect Effects - Index of Partial Moderated Mediation } \\
\hline- & Index & BootSE & BootLLCI & BootULCI & - & - \\
\hline $\mathrm{X} 1{ }^{*}$ MED TRUST & 0.070 & 0.099 & -0.123 & 0.296 & - & - \\
\hline X1 * GOVT TRUST & -0.134 & 0.083 & -0.322 & -0.006 & - & - \\
\hline X2 * MED TRUST & 0.018 & 0.105 & -0.207 & 0.244 & - & - \\
\hline X2 * GOVT TRUST & -0.027 & 0.057 & -0.159 & 0.074 & - & - \\
\hline X3 * MED TRUST & 0.078 & 0.111 & -0.123 & 0.323 & - & - \\
\hline X3 * GOVT TRUST & -0.072 & 0.064 & -0.223 & 0.026 & - & - \\
\hline
\end{tabular}

were the participants' political ideology (moderated by their trust in government) and their attitude certainty about the COVID-19 vaccine.

\section{GENERAL DISCUSSION}

The results of these two experiments extend existing literature by demonstrating that the effects of inoculation and psychological reactance are working in tandem to influence attitudes among individuals with neutral and opposed attitudes toward the COVID19 vaccine. Specifically, these findings suggest that perceived threat from an inoculation message on its own does not predict positive effects in this context; rather important psychological mediators may be triggering reactance and influencing these attitudinal outcomes.

For those who are mildly-to-strongly opposed to the vaccine, the key drivers predicting attitude change in this context are political ideology and attitude certainty. Thus, the challenge for public health 
communicators seeking to encourage vaccine uptake is to weaken anti-vaccine attitude certainty without triggering reactance. Negative response to both of the politicized messages indicates that using a credible but politically-neutral source is one critical element to be incorporated into effective message design.

While evidence of inoculation was demonstrated in terms of counterarguing intent among vaccine supporters, those who were neutral or opposed to the vaccine had less interest in sharing provaccine messages with their social network. Instead, the intent for opposed subjects was to discredit the message rather than share or support it. This finding suggests that reactance to the inoculation messaging was driving this response, since it countered their existing beliefs and likely threatened their perceived freedom. Thus, to foster positive word-of-mouth, pro-vaccine messaging must be designed to motivate all audiences to share it with their peers.

\section{Practical Implications}

For public health communicators, this work provides important insights about tailoring appropriate messaging and placements designed to increase willingness to take the COVID-19 vaccine. Notable differences were found between the different message conditions (inoculation vs control; politicized vs neutral source) among conservatives, who are considered the most important target audience in this context due to their greater vaccine hesitancy (Berg, 2020; Bynum, 2021). Specifically, the one-sided neutral message was the only one that was positively perceived by this critical audience, suggesting that attempts to persuade them with inoculation appeals featuring controversial, political figures will not be effective. Moreover, Motta et al. (2021) finding that messages originating from expert sources (especially political ones) are not as effective as messages from everyday Americans supports this interpretation. Additionally, the use of language that is perceived as threatening their freedom has been found to trigger reactance among those with opposing views and high attitude certainty (Miller et al., 2013; Richards et al., 2017). Therefore, tailoring messages to recipients based on their pre-existing attitudes and political ideology (Cakanlar et al., 2020), and incorporating nonthreatening, empathetic narratives (Reynolds-Tylus, 2019) should contribute to positive outcomes in this context.

Previous research suggests that one effective way to influence attitude certainty is through the use of a social media bandwagon strategy. Placing appropriately-tailored, pro-vaccine messages within social media groups attracting members who are opposed the vaccine (and offering these individuals an opportunity to interact with advocates) has been shown to reduce reactance and improve persuasion in other health communication contexts ( $\mathrm{Li}$ and Sundar, 2021). If properly executed, this type of two-way communication can be perceived as an educational information exchange rather than an attempt to bombard critics with one-way, manipulative messaging. Won et al. (2018) also found that public interest messaging shared through social networks are more effective than those posted only on official websites due to the potential of twoway interaction with audiences.

\section{Limitations and Future Directions}

A possible limitation of this study was the lack of significant time delay in measuring respondents' attitudes pre and post exposure.
Most inoculation studies gauge post-exposure effects following a 3-day delay, so future studies examining attitudes about the COVID-19 vaccine might incorporate a longitudinal design to further test these effects. Another limitation that may have influenced results was presenting the message as a social media post. Previous research indicates that information presented via social media does not generally attract the same level of credibility as other sources (Smith et al., 2019), suggesting the need to test future messaging across other media platforms.

Additionally, given the findings of recent scholars examining antecedents to attitudes about the COVID-19 vaccine, future studies might test persuasive message strategies incorporating frames based on personal responsibility (Cakanlar et al., 2020) or information seeking intent (Kelly et al., 2020) to determine if these factors play a role in attitude formation and change.

Given that more people have died from COVID-19 in the first half of 2021 than in all of 2020 (Kamp et al., 2021), combating misinformation and overcoming negative attitude certainty about the COVID-19 vaccine is imperative. Further research into inoculation-based message strategies that will not trigger reactance is needed to inform the design of more effective interventions. Evidence from this study suggests that tailoring messages to incorporate fact-based, choiceenhancing language, utilizing neutral, respected sources, and presenting it in effective platforms (with the potential to build positive bandwagon effects with likeminded peers) will be key to improving outcomes among those who are most vaccine hesitant.

\section{DATA AVAILABILITY STATEMENT}

The raw data supporting the conclusions of this article will be made available by the authors, without undue reservation.

\section{ETHICS STATEMENT}

The studies involving human participants were reviewed and approved by Office of Research Compliance, University of Alabama. The patients/participants provided their written informed consent to participate in this study.

\section{AUTHOR CONTRIBUTIONS}

The author confirms being the sole contributor of this work and has approved it for publication.

\section{FUNDING}

Funding for the publication of this article was provided by the University of Alabama. 


\section{REFERENCES}

Banas, J. A., and Rains, S. A. (2010). A Meta-Analysis of Research on Inoculation Theory. Commun. Monogr. 77 (3), 281-311. doi:10.1080/ 03637751003758193

Banas, J. A., and Richards, A. S. (2017). Apprehension or Motivation to Defend Attitudes? Exploring the Underlying Threat Mechanism in InoculationInduced Resistance to Persuasion. Commun. Monogr. 84 (2), 164-178. doi:10.1080/03637751.2017.1307999

Barrios, J. M., and Hochberg, Y. (2020). Risk Perception through the Lens of Politics in the Time of the COVID-19 Pandemic. National Bureau of Economic Research. Cambridge, United states.

Baumgaertner, B., Carlisle, J. E., and Justwan, F. (2018). The Influence of Political Ideology and Trust on Willingness to Vaccinate. PLoS One 13 (1), e0191728. doi:10.1371/journal.pone.0191728

Bechler, C. J., and Tormala, Z. (2020). Misdirecting Persuasive Efforts during the COVID-19 Pandemic: The Threats People Choose May Not Be the Most Likely to Change. J. Assoc. Consumer Res. 6 (1). doi:10.1086/711732

Benski, C., Goto, A., and Reich, M. R. (2020). Developing Health Communication Materials during a Pandemic. Front. Commun. 5, 603656. doi:10.3389/ fcomm.2020.603656

Berg, P. (2020). The COVID Confidence Conundrum. Gallup 19. https://news. gallup.com/poll/324080/covid-confidence-conundrum.aspx (Accessed June 25, 2021).

Braunstein, S., Charles, G., Croome, L., Fung, H., Kemp, H., Kumar, R., et al. (2021). COVID-19 Vaccine Uptake and Attitudes: An Analysis of COVID-19 Vaccination Intention and Concerns. Washington, DC, United States: Surgo Ventures. Available at: https://surgoventures.org/resource-library/surveyhealthcare-workers-and-vaccine-hesitancy (Accessed June 25, 2021).

Brehm, J. W. (1966). A Theory of Psychological Reactance. New York, NY: Academic Press.

Brehm, S. S., and Brehm, J. W. (1981). Psychological Reactance A Theory of Freedom and Control. The Encyclopedia of Cross-Cultural Psychology. New York, NY: Academic Press.

Bynum, R. (2021). Red States on Electoral Map Lagging on Vaccinations. New York, NY, United States: Associated Press. Available at: https://apnews.com/article/joebiden-donald-trump-alabama-georgia-savannah941ef2bf9b60ee39d6b9fd5e2ce861f7 (Accessed June 25, 2021)

Cakanlar, A., Trudel, R., and White, K. (2020). Political Ideology and the Perceived Impact of Coronavirus Prevention Behaviors for the Self and Others. J. Assoc. Consumer Res. 7 (1). doi:10.1086/711834

Centers for Disease Control (2021). COVIDView: A Weekly Surveillance Summary of U.S. COVID-19 Activity. Available at: https://www.cdc.gov/coronavirus/ 2019-ncov/covid-data/covidview/index.html.

Chan, Y. Y. Y., and Ngai, E. W. T. (2011). Conceptualising Electronic Word of Mouth Activity. Mrkting Intelligence \& Plan 29 (5), 488-516. doi:10.1108/ 02634501111153692

Chou, W. S., and Budenz, A. (2020). Considering Emotion in COVID-19 Vaccine Communication: Addressing Vaccine Hesitancy and Fostering Vaccine Confidence. Health Commun. 35 (14), 1718-1722. doi:10.1080/10410236.2020.1838096

Compton, J. A., and Pfau, M. (2005). "Inoculation Theory of Resistance to Influence at Maturity: Recent Progress in Theory Development and Application and Suggestions for Future Research," in Communication Yearbook (Mahwah, NJ: Routledge), 29, 97-145. doi:10.1207/s15567419cy2901_4

Compton, J., and Ivanov, B. (2012). Untangling Threat during InoculationConferred Resistance to Influence. Commun. Rep. 25, 1-13. doi:10.1080/ 08934215.2012.661018

Compton, J., Jackson, B., and Dimmock, J. A. (2016). Persuading Others to Avoid Persuasion: Inoculation Theory and Resistant Health Attitudes. Front. Psychol. 7, 122. doi:10.3389/fpsyg.2016.00122

Compton, J., and Pfau, M. (2009). Spreading Inoculation: Inoculation, Resistance to Influence, and Word-Of-Mouth Communication. Commun. Theor. 19 (1), 9-28. doi:10.1111/j.1468-2885.2008.01330.x

Cook, J., Lewandowsky, S., and Ecker, U. K. H. (2017). Neutralizing Misinformation through Inoculation: Exposing Misleading Argumentation Techniques Reduces Their Influence. PLoS One 12 (5), e0175799. doi:10.1371/journal.pone.0175799
Crawford, J. T. (2017). Are Conservatives More Sensitive to Threat Than Liberals? it Depends on How We Define Threat and Conservatism. Soc. Cogn. 35 (4), 354-373. doi:10.1521/soco.2017.35.4.354

Creitz, C. (2021). Dr. Anthony Fauci Takes Credibility Hit Among Republicans. Fox News, March 18 Available at: https://www.foxnews.com/media/trumpfauci-self-serving-liar-doctors-covid-vaccine.

DeMarree, K. G., Petty, R. E., Briñol, P., and Xia, J. (2020). Documenting Individual Differences in the Propensity to Hold Attitudes with Certainty. J. Personal. Soc. Psychol. 119 (6), 1239-1265. doi:10.1037/pspa0000241

Dillard, J. P., and Shen, L. (2005). On the Nature of Reactance and its Role in Persuasive Health Communication. Commun. Monogr. 72 (2), 144-168. doi:10.1080/03637750500111815

File, T., and Mohanty, A. (2021). Around Half of Unvaccinated Americans Indicate They Will 'definitely' Get COVID-19 Vaccine. Available at: https://www. census.gov/library/stories/2021/01/around-half-of-unvaccinated-americansindicate-they-will-definitely-get-covid-19-vaccine.html.

Gonella, F., Casazza, M., Cristiano, S., and Romano, A. (2020). Addressing COVID-19 Communication and Management by a Systems Thinking Approach. Front. Commun. 5 (63), 63. doi:10.3389/fcomm.2020.00063

Holland, R. W., Verplanken, B., and van Knippenberg, A. (2003). From Repetition to Conviction: Attitude Accessibility as a Determinant of Attitude Certainty. J. Exp. Soc. Psychol. 39 (6), 594-601. doi:10.1016/ s0022-1031(03)00038-6

Ipsos (2020). Three in Four Adults Globally Say They'd Get A Vaccine for COVID19. Available at: https://www.ipsos.com/en/three-four-adults-globally-saytheyd-get-vaccine-covid-19.

Irmack, C., Murdock, M., and Kanuri, V. (2020). When Consumption Regulations Backfire: The Role of Political Ideology. J. Marketing Res. 57 (5), 966-984. doi:10.1177/0022243720919709

Ivanov, B. (2018). "Inoculation Theory Applied in Health and Risk Messaging," in Encyclopedia of Health and Risk Message Design and Processing. Editor R. Parrott (New York City, NY: Oxford University Press).

Ivanov, B., Rains, S. A., Geegan, S. A., Vos, S. C., Haarstad, N. D., and Parker, K. A. (2017). Beyond Simple Inoculation: Examining the Persuasive Value of Inoculation for Audiences with Initially Neutral or Opposing Attitudes. West. J. Commun. 81 (1), 105-126. doi:10.1080/10570314.2016.1224917

Jost, J. T. (2017). Ideological Asymmetries and the Essence of Political Psychology. Polit. Psychol. 38 (2), 167-208. doi:10.1111/pops.12407

Kamp, J., Douglas, J., and Forero, J. (2021). COVID-19 Deaths This Year Have Already Eclipsed 2020's Toll. Wall Street J. Available at: https://www.wsj.com/ articles/covid-19-deaths-this-year-have-already-eclipsed-2020s-toll-11623350773 (Accessed June 25, 2021)

Kelly, S., Goke, R., McCall, M., and Dowell, S. G. (2020). Parasocial Relationships with President Trump as a Predictor of COVID-19 Information Seeking. Front. Commun. 5, 596663. doi:10.3389/fcomm.2020.596663

Kim, W. G., Han, J. S., and Lee, E. (2001). Effects of Relationship Marketing on Repeat purchase and Word of Mouth. J. Hospitality Tourism Res. 25 (3), 272-288. doi:10.1177/109634800102500303

Lee, J. K., Choi, J., Kim, C., and Kim, Y. (2014). Social media, Network Heterogeneity, and Opinion Polarization. J. Commun. 64 (4), 702-722. doi:10.1111/jcom. 12077

Leonhardt, D. (2021). Republicans Tend to Underestimate COVID Risks and Democrats Tend to Exaggerate Them. New York Times. Newyork. Available at: https://www.nytimes.com/2021/03/18/briefing/atlanta-shootings-kamalaharris-tax-deadline-2021.html (Accessed June 25, 2021).

Li, R., and Sundar, S. S. (2021). Can Interactive media Attenuate Psychological Reactance to Health Messages: A Study of the Role Played by User Commenting and Audience Metrics in Persuasion. Health Commun.

Lilienfeld, S. O., and Latzman, R. D. (2014). Threat Bias, Not Negativity Bias, Underpins Differences in Political Ideology. Behav. Brain Sci. 37 (3), 318-319. doi:10.1017/s0140525x1300263x

Maertens, R., Roozenbeek, J., Basol, M., and van der Linden, S. (2020). Long-term Effectiveness of Inoculation against Misinformation: Three Longitudinal Experiments. J. Exp. Psychol. Appl. 27, 1-16. doi:10.1037/xap0000315

McGill, M., and Sara Fischer, S. (2021). Facebook Says it Will Crack Down on COVID Vaccine Misinformation. AXIOS. Available at: https://www.axios.com/ facebook-says-it-will-crack-down-on-covid-vaccine-misinformation-3eadfa344f7d-46e1-b14b-5247424dbbf3.html (Accessed June 25, 2021). 
McGuire, W. J. (1964). "Some Contemporary Approaches," in Advances in Experimental Psychology. Editor L. Berkowitz (New York, NY: Academic Press), 1, 191-229. doi:10.1016/s0065-2601(08)60052-0

McGuire, W. J. (1961). The Effectiveness of Supportive and Refutational Defenses in Immunizing and Restoring Beliefs against Persuasion. Sociometry 24 (2), 184-197. doi:10.2307/2786067

McKnight, D. H., Choudhury, V., and Kacmar, C. (2002). Developing and Validating Trust Measures for E-Commerce: An Integrative Typology. Inf. Syst. Res. 13 (3), 334-359. doi:10.1287/isre.13.3.334.81

Miller, C. H., Ivanov, B., Sims, J., Compton, J., Harrison, K. J., Parker, K. A., et al. (2013). Boosting the Potency of Resistance: Combining the Motivational Forces of Inoculation and Psychological Reactance. Hum. Commun. Res. 39, 127-155. doi:10.1111/j.1468-2958.2012.01438.x

Motta, M., Sylvester, S., Callaghan, T., and Lunz-Trujillo, K. (2021). Encouraging COVID-19 Vaccine Uptake through Effective Health Communication. Front. Polit. Sci. 3. doi:10.3389/fpos.2021.630133

Nowlan, L., and Zane, D. M. (2020). Getting Conservatives and Liberals to Agree on the COVID-19 Threat. J. Assoc. Consumer Res.-000. doi:10.1086/711838

Panchal, N., Kamal, R., and Orgera, K. (2020). The Implications of COVID-19 for Mental Health and Substance Use. San Francisco, CA, United States: Kaiser Family Foundation. Available at: https://www.kff.org/coronavirus-covid-19/ issue-brief/the-implications-of-covid-19-for-mental-health-and-substance-use/ (Accessed June 25, 2021).

Pfau, M. (1995). "Designing Messages for Behavioral Inoculation," in Designing Health Messages: Approaches from Communication Theory and Public Health Practice. Editors E. Maibach and R. L. Parrott (Thousand Oaks, CA: Sage), $99-113$.

Pfau, M., Ivanov, B., Houston, B., Haigh, M., Sims, J., Gilchrist, E., et al. (2005). Inoculation and Mental Processing: The Instrumental Role of Associative Networks in the Process of Resistance to Counterattitudinal Influence. Commun. Monogr. 72, 414-441. doi:10.1080/03637750500322578

Pfau, M., Semmler, S. M., Deatrick, L., Mason, A., Nisbett, G., Lane, L., et al. (2009). Nuances about the Role and Impact of Affect in Inoculation. Commun. Monogr. 76 (1), 73-98. doi:10.1080/03637750802378807

Read, M. C. (2020). EID: High Contagiousness and Rapid Spread of Severe Acute Respiratory Syndrome Coronavirus 2. Emergent Infect. Dis. 26.

Reynolds-Tylus, T. (2019). Psychological Reactance and Persuasive Health Communication: A Review of the Literature. Front. Commun. 4, 56. doi:10.3389/fcomm.2019.00056

Richards, A. S., and Banas, J. A. (2015). Inoculating against Reactance to Persuasive Health Messages. Health Commun. 30 (5), 451-460. doi:10.1080/ 10410236.2013.867005

Richards, A. S., Banas, J. A., and Magid, Y. (2017). More on Inoculating against Reactance to Persuasive Health Messages: The Paradox of Threat. Health Commun. 32 (7), 890-902. doi:10.1080/10410236.2016.1196410

Roozenbeek, J., Schneider, C. R., Dryhurst, S., Kerr, J., Freeman, A. L. J., Recchia, G., et al. (2020). Susceptibility to Misinformation about COVID-19 Around the World. R. Soc. Open Sci. 7 201199. doi:10.1098/rsos.201199

Roozenbeek, J., and van der Linden, S. (2019). Fake News Game Confers Psychological Resistance against Online Misinformation. Palgrave Commun. 5, 65. doi:10.1057/s41599-019-0279-9
Seibel, C. A., and Dowd, E. T. (2001). Personality Characteristics Associated with Psychological Reactance. J. Clin. Psychol. 57, 963-969. doi:10.1002/jclp.1062

Smith, A., Silver, L., Johnson, C., and Jiang, J. (2019). Users Say They Regularly Encounter False and Misleading Content on Social media - but Also New Ideas. Washington, DC, United States: Pew Research Center. Available at: https:// www.pewresearch.org/internet/2019/05/13/users-say-they-regularlyencounter-false-and-misleading-content-on-social-media-but-also-new-ideas/ (Accessed June 25, 2021).

Tedin, K. L. (1987). Political Ideology and the Vote. Res. Micropolitics 2 (1), 63-94.

Tormala, Z. L., and Rucker, D. D. (2007). Attitude Certainty: A Review of Past Findings and Emerging Perspectives. Social Personal. Psychol. Compass 1 (1), 469-492. doi:10.1111/j.1751-9004.2007.00025.x

Tyson, A., Johnson, C., and Funk, C. (2020). U.S. Public Now Divided over whether to Get COVID-19 Vaccine, 17. Pew Research Center. Available at: https://www. pewresearch.org/science/2020/09/17/u-s-public-now-divided-over-whetherto-get-covid-19-vaccine/ (Accessed June 25, 2021).

Van der Linden, S., Leiserowitz, A., Rosenthal, S., and Maibach, E. (2017). Inoculating the Public against Misinformation about Climate Change. Glob. Challenges 1, 1600008. doi:10.1002/gch2.201600008

Van der Linden, S., Roozenbeek, J., and Compton, J. (2020). Inoculating against Fake News about COVID-19. Front. Psychol. 11. doi:10.3389/ fpsyg.2020.566790

Visser, P. S., and Mirabile, R. R. (2004). Attitudes in the Social Context: the Impact of Social Network Composition on Individual-Level Attitude Strength. J. Personal. Soc. Psychol. 87 (6), 779-795. doi:10.1037/0022-3514.87.6.779

Won, J., Hon, L., and Lee, A. R. (2018). Predicting Public Interest Issue Campaign Participation on, Social media. J. Public Interest Commun. 2 (1), 2573-4342.

Wood, M. L. M. (2007). Rethinking the Inoculation Analogy: Effects on Subjects with Differing Preexisting Attitudes. Hum. Comm Res 33 (3), 357-378. doi:10.1111/j.1468-2958.2007.00303.x

Wu, C., and Shaffer, D. R. (1987). Susceptibility to Persuasive Appeals as a Function of Source Credibility and Prior Experience with the Attitude Object. J. Personal. Soc. Psychol. 52 (4), 677-688. doi:10.1037/00223514.52.4.677

Conflict of Interest: The author declares that the research was conducted in the absence of any commercial or financial relationships that could be construed as a potential conflict of interest.

Publisher's Note: All claims expressed in this article are solely those of the authors and do not necessarily represent those of their affiliated organizations, or those of the publisher, the editors and the reviewers. Any product that may be evaluated in this article, or claim that may be made by its manufacturer, is not guaranteed or endorsed by the publisher.

Copyright $\odot 2022$ Brinson. This is an open-access article distributed under the terms of the Creative Commons Attribution License (CC BY). The use, distribution or reproduction in other forums is permitted, provided the original author $(s)$ and the copyright owner(s) are credited and that the original publication in this journal is cited, in accordance with accepted academic practice. No use, distribution or reproduction is permitted which does not comply with these terms. 